\title{
Revisión: necesidades nutricionales de peces de la familia Pimelodidae en Sudamérica (Teleostei: Siluriformes)
}

\author{
Mariana Catalina Gutiérrez-Espinosa, Juan Sebastian Velasco-Garzón \\ \& Carlos Arturo León-Morales \\ Grupo de Investigación en Acuicultura y Limnología, Facultad de Ciencias Agropecuarias y Recursos Naturales, \\ Universidad de los Llanos, Km 4 vía Puerto López Vereda Barcelona Unillanos, Villavicencio-Meta, Colombia; \\ mariana.gutierrez@unillanos.edu.co,jsvelasco17@gmail.com, calmaleon42@hotmail.com
}

Recibido 14-VI-2018. Corregido 21-X-2018. Aceptado 24-I-2019.

\begin{abstract}
Review: nutritional needs of South American Pimelodidae fish (Teleostei: Siluriformes). Nutritional requirements of Pimelodidae fishes in South America (Teleostei: Siluriformes). The Silurids, also known as catfish is one of the most representative groups of fish. Comprised of 31 families, 412 genera and approximately 2600 species, which places them, as the third among all orders of teleost of which 13 families (64 $\%$ of the species) living in South America. Within this order is the Pimelodidae, Eigenmann and Eigenmann family (1889), the most abundant in Neotropical siluriformes widely distributed in South and Central America. Some representatives of the Pimelodidae family are individuals whose specific characteristics make capable of being handled in captivity for commercial purposes. One of the main negative factors for profitable business is the lack of knowledge about, among other things, the basic elements to formulate well-balanced diets and to provide the fish with their basic nutritional requirements for an optimal development. For this reason, it is of paramount importance to make a general bibliography review of the main aspects related to food and nutrition of the family.
\end{abstract}

Key words: protein; lipid; energy; fish; Silurids; feed.

Gutiérrez-Espinosa, M. C., Velasco-Garzón, J. S., \& León-Morales, C. A. (2019). Revisión: necesidades nutricionales de peces de la familia Pimelodidae en Sudamérica (Teleostei: Siluriformes). Revista de Biología Tropical, 67(1), 146-163.

Los silúridos también conocidos como "bagres" o catfish (pez gato) es uno de los grupos más representativos de peces. En general se han diversificado para prosperar en aguas obscuras o turbias, reduciendo en esta forma interacciones por medio de la visión tal como sucede en cypriniformes y characiformes. Esta diversificación ha producido 31 familias, 412 géneros y 2600 especies aproximadamente, lo cual lo ubica, en extensión, como el tercero entre todos los órdenes de teleósteos, de las cuales, 13 familias y el $64 \%$ de las especies residen en sur américa (Provenzano, 2002).
Este grupo se caracteriza por tener un cuerpo elongado desprovisto de escamas o cubierto con placas óseas, presentan una piel lisa recubierta de mucosidad, que varía de intensidad en función de la especie (Ramírez \& Ajiaco, 2001). Su cabeza está cubierta por piel delgada y los huesos del cráneo son claramente visibles. En la mayoría de las especies el primer radio de las aletas dorsales y pectorales es rígido y punzante, causante de heridas dolorosas, que pueden trabar o inmovilizar en un lugar (Kraus, 1945 en Milles, 1971). Los catfish muestran el mayor rango de tamaño en adultos de cualquier 
grupo de peces óseos y puede ir desde los 12 $\mathrm{mm}$ de longitud total hasta más de $5 \mathrm{~m}$ (Moyle \& Cech, 2004; Provenzano, 2002).

Dentro del orden Siluriformes se encuentra la familia Pimelodidae, Eigenmann y Eigenmann (1889), uno de los grupos más abundantes de siluriformes neotropicales distribuidos ampliamente en América del Sur y Central. De esta familia actualmente se conocen más de 60 géneros y 300 especies distribuidas desde México hasta Argentina (Tallarico, 1997; Burgess, 1989; Ringuelet, Aramburu, \& de Aramburu, 1967). Milles (1971), resalta que esta familia se caracteriza por presentar una aleta adiposa siempre bien desarrollada y las aletas ventrales debajo de la dorsal. Dientes villiformes, dispuestos como las cerdas de un cepillo, que en algunas especies se encuentran situados en grupos en el paladar. Poseen siempre seis barbillas peribucales, dispuestas en dos pares mentoneales y un par maxilares siempre más largas y una vejiga aerífera grande.

Según Ringuelet et al. (1967) esta familia se distribuye en tres subfamilias: Sorubiminae (manduvés y surubíes), Luciopimelodinae (patíes) y Pimelodinae (bagres). Sin embargo, estudios recientes de sistemática filogenética proponen modificar esta clasificación dividiendo a los Pimelodidae en tres subfamilias: Pimelodinae, Rhamdiinae y Pseudopimelodinae, incluyendo al género Luciopimelodus, Eigenmann y Eigenmann 1888, en la subfamilia Pimelodinae (Lundberg, Linares, Antonio, $\&$ Nass, 1988), en contraposición con su ubicación dentro de Luciopimelodinae, de acuerdo con la taxonomía tradicional (Ringuelet et al., 1967). Estudios posteriores, proponen un origen polifilético para la tradicional familia Pimelodidae (Lundberg, Mago-Leccia, \& Nass, 1991; de Pinna, 1993), reconociendo tres linajes monofiléticos (Pimelodinae, Heptapterinae y Pseudopimelodinae), los que estarían más emparentados con otros grupos de Siluriformes que entre ellos mismos (de Pinna, 1998).

Estudios citogenéticos realizados en Pimelodidae (Ringuelet et al., 1967) muestran que la mayoría de las especies presentan 56 cromosomas como número diploide con variación entre 46 y 63, refiriéndose la mayoría de ellos a especies comprendidas en las subfamilias Sorubiminae y Pimelodinae (Días, 1987; Oliveira, Almeida-Toledo, Foresti, Britski, \& Toledo, 1988; Fenocchio \& Bertollo, 1992; Souza, Moreira-Filho, Corrêa, \& Castro, 1994; Vissotto, Foresti, \& Oliveira, 1994a; Vissotto, Maistro, Foresti, Oliveira, \& Carvalho, 1994b; Abumarca \& Martins-Santos, 1996; Fenocchio, Cano, Sánches, Pastori, \& Alberdi, 1996; Shibatta \& Dias, 1996; Swarça, Dias, \& Giuliano-Caetano, 1996; Tambani Da Silva Dias, \& Giuliano-Caetano, 1996; Vissotto, Foresti, \& Oliveira, 1996).

Beltrán y Lamus (1975) resaltan que estos peces son susceptibles a migraciones, denominándoseles especies reofílicas o reófilas. Arboleda (1989) destaca que esta familia es de niveles tróficos altos, siendo en su mayoría predadores, ictiófagos y omnívoros. Un dato interesante es la existencia de cantidad de estómagos vacíos, que pueden sugerir que estos bagres dejan de alimentarse durante la última fase de su ciclo reproductivo (Arboleda, 1989).

Según el Servicio Estadístico Pesquero Colombiano (Roca-Lanao, Polonia-Rivera, Altamar, Duarte, \& Manjarrés-Martínez, 2016) la producción acuícola comprendida entre julio y diciembre de 2016 fue de 326424 toneladas, dentro de las cuales se incluyen la actividad extractiva, producción en granjas y las importaciones. Dentro de estos valores la participación en el mercado de la familia Pimelodidae constituye una producción de 67183 toneladas correspondientes a este período. Resaltando las principales especies con mayor importancia comercial como son el Pseudoplatystoma spp. Pimelodus grosskopfii, Pimelodus albicans, Brachyplatystoma rousseauxii, Hypophthalmus fimbriatus, Zungaro zungaro, entre otros. Estos valores demuestran la importancia comercial de la familia Pimelodidae en la industria acuícola en Colombia.

En esta revisión se presenta una recopilación bibliográfica general de los principales aspectos relacionados con la alimentación y nutrición de los silúridos y específicamente de la familia Pimelodidae. 


\section{Generalidades de los hábitos alimenticios}

Menin y Mimura (1992) muestran en sus trabajos la importancia de estudiar la anatomía del sistema digestivo, ya que permite establecer una relación entre el comportamiento del intestino y los hábitos alimenticios. Desde el punto de vista bioquímico, la función básica de este sistema consiste en disolver o transformar los constituyentes del alimento en subunidades estructurales básicas. Las características anatómicas del aparato digestivo se encuentran en estrecha dependencia con la naturaleza del alimento, las características del hábitat, el estado nutricional y el desarrollo del individuo, siendo manifestadas especialmente a través de adaptaciones y modificaciones en este (de Seixas Filho et al., 2001b).

En el grupo de los silúridos se observa una amplia diversidad trófica, encontrándose desde detritívoros, pasando por omnívoros hasta netamente carnívoros. Como ejemplo de una especie carnívora esta Hemisorubim platyrhynchos, familia Pimelodidae, la cual es migratoria sin cuidado parental que está ampliamente distribuida en la región neotropical, con reportes que indican su presencia en las cuencas de los ríos Orinoco, Amazonas, Paraguay, Uruguay y Paraná; es un pez valioso para la acuicultura debido a la calidad, el sabor de su carne y la ausencia de huesos intramusculares. Faccioli et al. (2016) describieron la organogénesis del sistema digestivo de $H$. platyrhynchos desde la eclosión hasta los 21 días de vida y encontraron que el sistema digestivo durante los primeros días es suficiente para permitir la ingestión y digestión de los alimentos, a través de la aparición de pliegues y células caliciformes en el esófago, un intestino sacular anterior y desarrollo del hígado y páncreas. La amplia diversidad trófica se basa en el comportamiento alimenticio, morfología del tracto gastrointestinal y fisiología digestiva, aunque no solo esta diversificación del grupo dificulta el acercamiento a la precisión de hábitos en las diferentes especies. Las referencias disponibles para casos específicos también pueden generar dificultades interpretativas. Por ejemplo, en el caso del yaque, Leiarius marmoratus, la revisión de Acosta-Santos, Agudelo-Córdoba, Ajíaco y Ramírez Gil (2011) lo califica como omnívoro con tendencia carnívora (con los ítems de peces, camarones y algunas semillas como los de mayor frecuencia), basándose en ejemplares provenientes de la cuenca del Amazonas; mientras, que para la misma especie, pero en la cuenca del Orinoco Ramírez y Ajiaco (2011) indican un espectro trófico mayor, en el que es más relevante la presencia de semillas y frutos que la de componentes de origen animal; en ese sentido, los autores prefieren calificarlo como omnívoro estricto, basando su conclusión en la relación longitud intestinal/longitud estándar. Bajo otra interpretación, en la Orinoquia venezolana esta especie es considerada ictiófaga en el estudio de Layman, Winemiller, Arrington y Jepsen (2005).

Estudio realizado por Abes, Agostinho, Okada y Gomes (2001), en el reservorio Itaipu, en el Rio Paraná, encontraron que Iheringichthys labrosus es una especie bentófaga alimentado con una amplia variedad de invertebrados acuáticos, esto podría ser el resultado de la abundancia de alimentos, o las restricciones de ingesta debido a la morfología bucal y aparatos digestivos. Fagundes, Behr y Kotzian (2008) plantean que la especie podría tener preferencia por ambientes lóticos, el espectro y el ritmo de alimentación probablemente fueron influenciados por las características particulares de cada hábitat y su diversidad y abundancia de organismos, y ciertamente por el hábitat típico y el ciclo de vida de las presas. Sin embargo, la especie mostró algunas variaciones temporales y espaciales a los otros alimentos. Se detectaron diferencias significativas en el ritmo alimentario en relación con las estaciones, el ritmo circadiano y los entornos (lentico, lótico), pero I. labrosus muestra una alta adaptabilidad a los diferentes entornos del río. Para Pimelodus maculatus existen estudios que reportan que es una especie con hábitos de alimentación omnívoras con tendencia a carnívora (Duarte, Bemquerer, \& Araújo, 2015).

Dentro de los vertebrados, los peces poseen el más simple y menos diferenciado sistema 
digestivo (De silva \& Andersson, 1995), sin embargo, la morfología del tubo digestivo es bastante variable, e indica la diversidad de regímenes alimenticios y modos de vida (de Seixas Filho et al., 2001b). En general la estructura de los órganos de los peces es similar a los demás vertebrados superiores. Pero, morfológica y fisiológicamente, presentan ciertas particularidades especialmente, si se tiene en cuenta que viven en un medio acuático que determina ciertas especializaciones que faltan en los animales terrestres. En el estudio realizado por Hernández, Pérez Gianeselli y Domitrovic (2009) en Rhamdia quelen, en el que analizan algunos parámetros morfométricos del tracto digestivo encontraron que la disposición morfológica de éste es compatible con los de peces carnívoros por su disposición un tanto rectilínea, pero el segmento convoluto puede ser visto como una adaptación a un régimen omnívoro con tendencia carnívora (de Seixa Filho, Fonseca, Oliveira, Donzale, \& Menin, 2001a). Si bien, $R$. quelen tiene un intestino relativamente corto, el segmento convoluto retardaría el avance del alimento, proporcionando de esta manera un mayor período digestivo. Para el caso de especies con hábitos netamente piscívoros como es el Pseudoplatystoma. corruscans, de Seixas Filho et al. (2001a) confirmaron que la disposición intestinal es compatible con la de los peces carnívoros, teniendo en cuenta que el intestino es casi recto, pero presenta algunas peculiaridades, tales como las circunvoluciones de bucles extremos del intestino medio, lo que podría ser visto como adaptaciones potenciales para un omnívoro. Según estos autores, la relación entre la disposición de pliegues de la mucosa y la tasa de transporte de alimento en el intestino medio sugiere que el patrón longitudinal con numerosas anastomosis demora el progreso de la alimentación en la dirección aboral, permitiendo un período más largo de digestión y, en consecuencia, mejor utilización de nutrientes. En los peces, la morfología del tracto gastrointestinal por lo general muestra variaciones específicas relacionadas con la dieta, el hábito de alimentación y la forma del cuerpo. Generalmente las especies detritívoras y herbívoras tienen intestinos más largos, más delgados y más estrechos que los carnívoros (Fugi, Agostinho, \& Hahn, 2001), mientras que el intestino de especies omnívoras tienen una longitud intermedia (Ward-Campbell, Beamish, \& Kongchaiya, 2005). Ward- Campbell et al. (2005) encontraron que el cociente intestinal por debajo de uno indica una dieta carnívora, entre uno y tres indican una dieta omnívora y más de tres una dieta herbívora o detritívora. Para especies de silúridos como el $P$. fasciatum, Rodrígues et al. (2010) reportan un coeficiente intestinal de $0.75 ;$ P corruscans de 0.46 (de Seixas Filho et al., 2001b); R. quelen 0.65 (Becker et al., 2010); L. marmoratus de 1.6 (Ramírez \& Ajiaco, 2011) y Pimelodus maculatus de 1.5 (Duarte et al., 2015).

En Pseudoplatystoma coruscans, el pintado, que se ubica frecuentemente en las bahías de los ríos Paraguay - Uruguay y San Francisco, estudios sobre el contenido estomacal han indicado que su hábito alimenticio es preferencialmente piscívoro (Gonçalves \& Carneiro, 2003), presentando un estómago bien definido y un intestino muy corto, siendo estas características compatibles con la mayoría de los peces carnívoros (Lundstedt, Melo, \& Moraes, 2004) y con hábitos nocturnos (Cardoso \& Volpato, 2005).

Gonçalves y Carneiro (2003) determinaron los coeficientes de digestibilidad de la fracción proteica y de la energía de las principales materias primas utilizadas en la alimentación del P. coruscans, presentando los mejores coeficientes en cuanto a la fracción proteica para la harina de pecado, $84.14 \%$, torta de soya, $67.10 \%$, maíz, $64.18 \%$, y la harina de vísceras de aves, $61.25 \%$, y los coeficientes más bajos para la harina de sangre $10.47 \%$ y la harina de plumas, $39.36 \%$. Con respecto a los coeficientes de digestibilidad de la energía las mejores medias fueron para la harina de pescado, 72.81 \%, maíz, $57.39 \%$, soya integral tostada, 64.95 $\%$, torta de soya, $61.66 \%$, torta de trigo, 53.20 $\%$ y torta de arroz, $51.84 \%$. Con respecto a lo anterior la harina de pescado se presenta como el mejor ingrediente para la elaboración de dietas para $P$. coruscans, esto posiblemente se 
deba a que la principal fuente de alimento en medio natural para esta especie son los peces, habiendo desarrollado de esta forma las enzimas necesarias para poder desdoblar y aprovechar eficientemente los nutrientes contenidos en el alimento.

Valbuena-Villareal, Zapata-Berruecos y Gutiérrez-Espinosa (2012) determinaron la digestibilidad aparente de la proteína y energía digestible de tres ingredientes usados en la fabricación de dietas para Pimelodus grosskopfii. Encontrando que los mayores resultados de coeficiente de digestibilidad aparente (CDA) de la proteína son para la harina de pescado $94.5 \pm 5.7 \%$, harina de sangre del $78.5 \pm 20.9 \%$ y menor para la harina de carne con $59.6 \pm 10.1$ \%. Para los CDA de la energía los mayores valores se presentaron en la harina de pescado $96.5 \pm 11.0 \%$, harina de sangre $78.7 \pm 10.9 \%$ y menor para la harina de carne con $61.1 \pm 13.0 \%$.

Lundstedt et al. (2004) publicaron los primeros estudios sobre enzimas digestivas del P. coruscans, con el fin de conocer las características de adaptación de estas enzimas y las respuestas metabólicas que siguen como resultado de la digestión, concluyendo que el nivel de proteasas digestibles no puede ser usado como modelo para establecer el nivel óptimo de proteína dietaría. La actividad amilasa, una enzima inductiva en la especie, puede ser ajustada a través del nivel de almidón de la dieta. $P$. coruscans es un pez carnívoro, que es capaz de consumir almidón de maíz. Sin embargo, aún es necesario hacer óptimo el balance proteína energía para aumentar el crecimiento y evitar pérdidas económicas.

Según el estudio de Lundstedt et al. (2004), la digestibilidad enzimática del $P$. coruscans es inusual comparada con otras especies. La alta actividad proteolítica en el estómago esta ciertamente asociada con los hábitos alimenticios de la especie y la estructura en el proceso digestivo. De Seixas Filho et al. (2001a), verificaron la presencia de células endocrinas en el intestino medio y posterior y en los ciegos pilóricos del pintado, $P$. coruscans, siendo esto un mecanismo de control de la absorción de los nutrientes del alimento.
Los estudios de evacuación gástrica, tal como lo plantean Marques, Agostinho, Sampaio y Agostinho (1992), se constituyen en requisitos básicos para la evaluación de la tasa de consumo alimenticia y el cálculo de la ración diaria a ser suministrados en las especies en cautiverio.

Otra de las especies de la familia Pimelodidae, es el Pimelodus maculatus, Santos et al. (2007) basados en la morfología del tracto digestivo, indican que esta especie presenta un patrón característico de un omnívoro. Otros autores afirman que presenta una notable plasticidad trófica, siendo una especie eurifágica, pero con preferencia por el consumo de insectos acuáticos (Lima-Junior \& Goitein, 2004; Andrade \& Braga, 2005).

\section{Requerimientos nutricionales}

Algunos representantes de la familia Pimelodidae son individuos cuyas características específicas los hacen aptos para ser manejados en cautividad con fines comerciales. Uno de los principales factores negativos para hacer rentable este ejercicio comercial es la falta de conocimiento relacionado, entre otras cosas, con los elementos básicos que permitan formular dietas equilibradas que aporten al individuo los requerimientos nutricionales básicos para un óptimo desarrollo.

Para poder establecer las exigencias nutricionales de las especies es necesario estudiar el hábito alimenticio en su ambiente natural, que hace referencia a la manera de alimentarse el pez, es decir de la conducta directamente relacionada con la búsqueda e ingestión de alimentos, lo que proporciona información para estimar el funcionamiento trófico en el ecosistema, es decir, el conjunto de relaciones de depredación y competencia entre organismos (Pereira, Smith, \& Espindola, 2004) haciendo de esta manera más fácil la formulación de dietas para manejar las especies en cautiverio.

A pesar de que el Catfish, Ictalurus punctatus no pertenece a la familia Pimelodidae, es una de las especies de silúridos más estudiada en cuanto a los requerimientos nutricionales 
y es importante tenerla en cuenta (Tucker \& Robinson, 1991).

Para determinar los requerimientos nutricionales en peces es necesario analizar en todos los aspectos detalles tales como, palatabilidad, tamaño de la partícula, estabilidad en el agua, concentración de nutrientes y energía (NRC, 1993; Lovell, 1998). Este proceso inicial se debe hacer con dietas experimentales, que deben ser formuladas con ingredientes semipurificados de composición química bien definida, permitiendo el control completo del efecto del nutriente evaluado. La formulación de esta dieta, también llamada dieta referencia asegura que su digestibilidad sea alta, prácticamente total. Los principales ingredientes utilizados en estas dietas se presentan en el Cuadro 1 (Fracalossi, Oeda, Silva, \& Cyrino, 2013).

\section{CUADRO 1}

Principales ingredientes utilizados para la formulación de dietas semipurificadas

TABLE 1

Principals ingredients used for the formulation of semipurified diets

Ingredientes

\section{Proteicos}

Caseína

Caseína con bajo nivel vitamínico

Gelatina

Albumina

\section{Energéticos}

Dextrina

Almidón de maíz

Aceites vegetales

Aceite de pescado

Aglutinantes

Carboximetilcelulosa

Agar

Hemicelulosa

Mezcla vitamínica-mineral

Otros

Celulosa

\section{Proteína}

Las proteinas son péptidos de elevado peso molecular, compuestas por carbono, hidrógeno, oxígeno, nitrógeno y con frecuencia azufre. Las unidades fundamentales de estas son los aminoácidos, los cuales pueden unirse entre sí por un enlace peptídico covalente entre el $\alpha$-carboxilo final de un aminoácido y el $\alpha$-amino final del otro. Los aminoácidos pueden enlazarse variando su secuencia para formar una vasta diversidad de proteínas (NRC, 2011).

Las proteínas constituyen un componente fundamental de los organismos vivos, particularmente, son la base estructural de la materia viva y por ello esencial para el mantenimiento y crecimiento, del 65 al $75 \%$ del total de materia seca del cuerpo de un pez está compuesto por esta molécula (Portz \& Furuya, 2013). A nivel de mantenimiento, el pez requiere proteína para reponer tejidos desgastados y productos proteicos como células epiteliales, enzimas y hormonas, esenciales para el funcionamiento correcto del organismo, las cuales recirculan velozmente, es decir que están formándose y degradándose continuamente. La capacidad del pez para sintetizar proteína de novo a partir de esqueletos de carbono es limitada, por lo tanto, la mayor parte de ella debe obtenerse del alimento. En el proceso fisiológico de digestión, la proteína es digerida e hidrolizada liberando aminoácidos, los cuales son absorbidos por el tracto intestinal y distribuidos por la sangre para todos los órganos y tejidos. Por lo tanto, el continuo suministro de este nutriente es las cantidades ideales para el pez es necesario para un perfecto crecimiento. El contenido de proteína en la dieta y el valor que se obtiene de dividir esta cifra entre la energía metabolizable son de fundamental importancia (Hepher, 1993; Portz \& Furuya, 2013). La evaluación de la relación proteína: energía para peces ha sido ampliamente estudiado para proporcionar valores eficiencia de proteína y energética de las dietas para mejorar el crecimiento y disminuir la liberación de compuestos nitrógeno al medio ambiente. El uso de proteínas de la dieta por parte de los peces para el crecimiento corporal se debe maximizar. Por lo tanto, evaluar la relación proteínas: lípidos como efecto ahorrador de proteína (protein-sparing) tiene gran importancia. Los efectos 
de la relación proteína:lípidos no han sido estudiados frecuentemente en peces tropicales carnívoros (Campeche, Andrade, Souza, Melo, \& Bezerra, 2018).

La estimación de los requerimientos proteicos se basa en la ganancia total de peso de los peces alimentados con dietas prácticas o semipurificadas. Cornélio, da Cunha, Silveira, Alexandre, Silva y Fracalossi (2014) establecieron el requerimiento de proteína en juveniles de $P$. reticulatum con peso entre 16 y $85 \mathrm{~g}$, evaluando 6 niveles de proteína entre 30 a 55 $\%$. Este experimento tuvo una duración de 60 días y concluyeron que el nivel de proteína con el que se obtuvo la mayor ganancia de peso fue $49.25 \%$. Esto es equivalente a $44.79 \%$ proteína digestible y relación proteína:energía bruta de $10.27 \mathrm{kcal} / \mathrm{g}$. Para P. coruscans (Pintado), Machado (1999), concluye que "el pintado al parecer no exige niveles proteicos superiores al $30 \%$, desde que la energía sea suficiente" [sic], esto posteriormente fue cuestionado por Cyrino, Fracalossi y Roubach (2013) quienes explican que tanto la metodología como el análisis presentaron errores. Posteriormente, Carneiro y Gonçalves (2002), determinaron que el nivel de proteína digestible requerido para esta especie es del $32 \%$. Reportes en la literatura muestran una notable diferencia en requerimientos de proteína, para juveniles (un rango de peso de 1 a $120 \mathrm{~g}$ ) de varias especies de Pseudoplatystoma, el cual va de 36 a 49 \% (Campos, Martino, \& Trugo, 2006; Zanardi, Boquembuzo, \& Koberstein, 2008; Silva, 2013; Cornélio et al., 2014; Gonçalves, 2014).

En la especie Pseudoplatystoma punctifer, Darias et al. (2015), evaluaron la influencia de diferentes niveles de proteína y lípidos y la relación entre estos, sobre el crecimiento de larvas y la incidencia de canibalismo. Las dietas contenían niveles de proteína:lípidos de 30:15, 30:10, 45:15 o 45:10. Los resultados mostraron alto crecimiennto y memor incidencia de canibalismo en el grupo alimentado con los niveles 45:15 en la dieta.

Para Rhamdia quelen, especie que se encuentra desde el sudoeste de México hasta el centro de Argentina (Baldisserotto \& Neto,
2005), existe información sobre el nivel óptimo de proteína en la dieta que varía entre el 28 y $51 \%$ de proteína bruta (Cuadro 2), se debe a diferencias en el tamaño de los peces, la digestibilidad y palatabilidad de los ingredientes que conformaban las dietas, el balance de aminoácidos, la relación energía:proteína, la tasa de alimentación, los parámetros analizados y los factores ambientales (Neto \& de Borda, 2013). Para animales de $0.3 \mathrm{~g}$ de peso alimentados con dieta práctica Melo, Lundstedt, Metón, Baanante y Moraes (2006) reportan un requerimiento de proteína del $41 \%$ con nivel de energía bruta (EB) de $4500 \mathrm{kcal} / \mathrm{kg}$, sin embargo, para la misma especie con individuos de igual tamaño Salhi, Bessonart, Chediak, Bellagamba y Carnevia (2004) establecieron, con dietas mixta (es decir dieta que contenida ingredientes de prácticos y semipurificado), el requerimiento proteico en $37 \%$ y nivel de energía digestible (ED) $3394 \mathrm{kcal} / \mathrm{kg}$. Coldebella et al. (2011), evaluaron el efecto de la concentración proteica de la dieta sobre el crecimiento, desempeño productivo y parámetros hematológicos de $R$. quelen en sistema de jaulas, los resultados indicaron exigencia menor a la de los estudios mencionados anteriormente.

La alimentación para Leiarius marmoratus en ambientes confinados se basa en el suministro de concentrados comerciales formulados para otras especies con niveles de proteína bruta empíricos que varían entre el 24 y 36 $\%$. Murillo-Pacheco et al. (2012) evaluaron la ganancia total de peso, la ganancia diaria de peso, la conversión alimenticia, la tasa de crecimiento específica, el factor de crecimiento relativo) y la sobrevivencia de L. marmoratus, bajo condiciones de cultivo en estanques de tierra, alimentándolo con tres diferentes niveles de proteína bruta (PB) en la dieta $(24,30$ y $34 \%)$, estas dietas correspondían a alimento comercial para tilapia, con base en los resultados concluyeron que el nivel de PB de la dieta afectaba el desempeño productivo del L. marmoratus, presentándose los más altos índices productivos cuando se ofreció la dietas con el $24 \%$ de PB. Mora-Sánchez, Moyetones y Jover (2009) realizaron un ensayo de alimentación para 

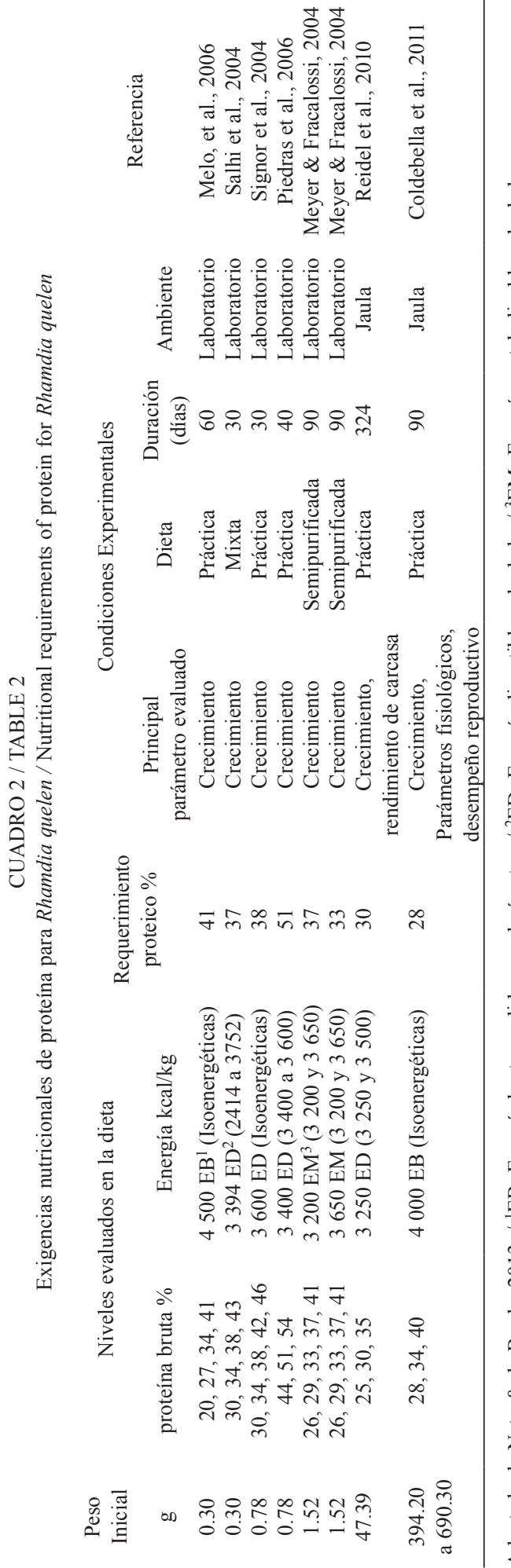

evaluar el efecto de proteína bruta (de 28, 32 y $36 \%$ ) del alimento comercial extrusados sobre el crecimiento de esta misma especie (individuos de $20 \mathrm{~g}$ ), concluyendo que los niveles de proteína tuvieron el mismo efecto sobre el crecimiento, conversión del alimento, tasa de alimentación diaria, coeficiente térmico de crecimiento y coeficiente de eficiencia proteica.

De Souza et al. (2017) evaluaron el desempeño de un híbrido (Pseudoplatystoma reticulatum x Leiarius marmoratus) alimentado con dietas que contenían 32 o $40 \%$ de proteína bruta (PB), analizaron el desempeño, rendimiento de los peces eviscerados, rendimiento del filete y el índice de grasa visceral. El tratamiento con $40 \%$ PB proporcionó mayor desempeño productivo para este híbrido. Sin embargo, aumento el acúmulo de grasa visceral.

\section{Energía}

Cuando se habla de energía se hace referencia a un proceso dinámico cambiante destinado a producir trabajo. La energía no es un nutriente, sin embargo, es liberada durante la oxidación metabólica de estos. Por ello para varias especies han sido determinadas las exigencias dietarias de los nutrientes conjuntamente con las exigencias de energía. Como principio general, los animales comen para satisfacer sus necesidades energéticas esenciales (metabolismo básico, actividades rutinarias, crecimiento, reproducción).

La fuente original de energía es el sol, a través del proceso de fotosíntesis los cloroplastos de las plantas verdes capturan la energía lumínica y la fijan convirtiéndola en energía química. La energía química contenida en el alimento puede ser cuantificada en unidades de calor; la unidad básica de energía calorífica es la caloría, la cual es la cantidad de energía calorífica para elevar la temperatura de 1 gr de agua $1{ }^{\circ} \mathrm{C}$ (14.5-15.5). El total de energía contenida en una sustancia es determinado oxidándola completamente hasta bióxido de carbono. La cantidad de calor resultante de esta oxidación es conocida como calor de combustión o valor energético bruto. 
La energía que sustenta las funciones metabólicas en los peces es básicamente originaria de las fuentes de lípidos y sus constituyentes, los ácidos grasos que, con la proteína, representan los principales nutrientes esenciales para estos animales (Portz \& Furuya, 2013).

De acuerdo con Britz y Hecht (1997), para que un pez cultivado pueda desarrollarse a su máxima capacidad de crecimiento, la tasa de deposición de proteína también debe ser máxima; esto solamente es posible cuando las dietas consumidas contienen energía digestible y proteína en las proporciones adecuadas.

Un desequilibrio en el balance Proteína/ Energía digestible (P/ED) por deficiencia de $\mathrm{ED}$, conduce a procesos catabólicos de desaminación, es decir, a la utilización de los aminoácidos como fuentes de energía para cubrir sus exigencias y no para canalizarlos en la síntesis de nuevos tejidos (Elangovan \& Shim, 1997; Samantaray \& Mohanty, 1997; da Cunha, Cornélio, \& Fracalossi, 2015). En contraste, el exceso de energía provoca una disminución en el consumo de materia seca y de esta forma reduce la ingestión de proteína y de otros nutrientes esenciales en las cantidades necesarias para máximo crecimiento (NRC, 1993; da Cunha et al., 2015). Tal desequilibro, también puede conducir a una deposición excesiva de grasa en el cuerpo de los peces, lo que desmejora, en términos de comercialización, la calidad del producto.

El conocimiento de los valores de Energía digestible ED de las materias primas comúnmente usadas en dietas para peces, es esencial para optimizar la utilización de las raciones formuladas para peces (Kaushik \& Médale, 1994; Kim \& Kaushik, 1992).

da Cunha et al. (2015), evalúan dietas isoproteícas (49\% de proteína bruta) con niveles crecientes de energía bruta (3.696, 4.049, $4.343,4.828$ y $5.232 \mathrm{kcal} / \mathrm{kg}$ ) en juveniles de Pseudoplatystoma reticulatum $(84.43 \pm 13.59$ $\mathrm{g}$ ), concluyendo que para una máxima ganancia de peso diario, la exigencia energética digestible estimada era de $3.497 \mathrm{kcal} / \mathrm{kg}$, es decir que a la relación de energía digestible:proteína digestible fue de $8.08 \mathrm{kcal} / \mathrm{g}$.
Baldisserotto y Neto (2005), plantean para Rhandia que la relación ED/PD para dietas con $28-32 \%$ de proteína es de 11.8 y $10.3 \mathrm{kcal} / \mathrm{g}$ de proteína digestible. Sin embargo, al igual que con los requerimientos de proteína, existe información sobre el nivel óptimo de energía en la dieta que varía entre 3200 y $4500 \mathrm{kcal} /$ $\mathrm{kg}$ (Cuadro 2), esto se debe a diferencias en el tamaño de los peces, la digestibilidad y palatabilidad de los ingredientes que conformaban las dietas, la relación energía:proteína, la tasa de alimentación, los parámetros analizados y los factores ambientales (Neto \& de Borda, 2013).

Machado (1999) fija como adecuada una relación energía:proteína de $13.34 \mathrm{kcal} / \mathrm{kg}$ para P. corruscans, es decir que una dieta con $30 \%$ de proteína bruta debe contener $4000 \mathrm{kca} / \mathrm{kg}$ de energía bruta.

Aunque existen algunos estudios de requerimientos de la fracción proteica en especies de silúridos, en cuanto a requerimientos energéticos no han sido bien estudiados, por lo que en cultivo han tenido en cuenta los resultados obtenidos para otras especies (Gonçalves \& Carneiro, 2003; Boscolo, Hayashi, \& Meurer, 2002; Gaylord \& Gatlin, 2001; Wilson \& Poe, 1985).

\section{Lípidos}

Los lípidos constituyen un conjunto heterogéneo de sustancias, que como los carbohidratos y proteínas están relacionados íntimamente con la materia viva; comprende grasas, aceites, fosfolípidos, esteroles, ácidos grasos, entre otros. La literatura sobre lípidos en peces es amplia pero incompleta, varios aspectos de su metabolismo son desconocidos y deducidos de conocimientos sobre los mamíferos y otros animales (Garcia, Goncalves, Cavalli, \& Viegas, 2013). La importancia de los lípidos está directamente relacionada con las múltiples funciones que desempeña: i) principal fuente de energía metabólica para peces, ii) responsables directos en el mantenimiento de la estructura, permeabilidad y estabilidad de las membranas celulares, iii) fuentes de ácidos grasos esenciales, iv) transportadores de otros 
nutrientes, y v) precursores de hormonas y otras moléculas bioactivas; son bien metabolizados por los peces y se requieren para lograr buenas tasas de crecimiento y desarrollo (Martino, Cyrino, Portz, \& Trugo, 2002a; Garcia et al., 2013). Como ejemplo de la función de mantenimiento de la estructura, permeabilidad y estabilidad de las membranas celulares, es importante resaltar lo reportado, por Faccioli et al. (2018), en la especie $H$. platyrhynchos en la cual, el tracto digestivo presenta ácidos glicoconjugados, lo que promueve la lubricación de la superficie epitelial para facilitar el paso de los alimentos y la protección contra la auto digestión y los patógenos. Los gránulos de células epiteliales gástricas están compuestos de lípidos que actúan en la protección epitelial. Las células oxinticopépticas de las glándulas gástricas mostraron gotitas de lípidos en el citoplasma y la matriz mitocondrial, que actúan como reserva de energía para estas células que tienen una alta demanda energética. Además, los enterocitos mostraron un retículo endoplásmico liso bien desarrollado, particularmente en la región apical de la célula, que se asoció con la resíntesis de lípidos.

Cuando los niveles de lípidos en la dieta están por encima de los requisitos metabólicos, podría ser almacenado como grasa visceral. Dietas con altos valores de lípidos pueden afectar la actividad de la lipasa, los niveles de colesterol y triglicéridos y causar disminución del crecimiento (Campeche et al., 2018).

Al igual que la proteína, para establecer el requerimiento de lípidos se evalúa el crecimiento de los individuos se puede clasificar en tres categorías: i) cantidad de lípidos exigida como fuete de energía, y en términos ii) cuantitativos y iii) cuantitativo de ácidos grasos esenciales (Sargent, Tocher, \& Bell, 2002). Reportes en la literatura muestran una notable diferencia en requerimientos de lípidos para juveniles (peso inicial entre 1 y $120 \mathrm{~g}$ ) de varias especies de Pseudoplatystoma, estando el nivel óptimo entre un rango desde 8 a $19 \%$ de lípidos (Martino, Cyrino, Portz, \& Trugo 2005; Campos et al., 2006; Arslan, Dabrowski, Ferrer, Dietrich, \& Rodriguez 2013; Silva, 2013;
Darias et al., 2015). Martino et al. (2002a) y Martino, Cyrino, Portz y Trugo (2002b), determinaron el efecto del nivel de lípidos en la dieta $(6,10,14$ y $18 \%)$ sobre el desempeño de $P$. coruscans, los peces alimentados con la dieta con $6 \%$ de lípidos presentaron el más bajo desempeño, mientras que los peces alimentados con el nivel más alto de lípidos mostraron el mejor rendimiento nutricional, concluyendo que el mejor resultado fue presentado en los individuos alimentados con la dieta que contenía $18 \%$ de lípidos. En esa especie otros trabajos ratifican que en raciones de $46 \%$ PC y con inclusión creciente de lípidos de 10.1 a $18.1 \%$, a base de grasa de cerdo o aceites de linaza o maíz, se obtuvo una mejora significativa de la conversión de alimento (Campos et al., 2006). Campeche et al. (2018) evaluaron el efecto de diferentes relaciones proteína:lípidos (9.00, 4.60, 3.54 y 1.78) sobre el crecimiento, enzimas digestivas, perfil metabólico y parámetros hematológicos en juveniles de hibrido Pseudoplatystoma corruscans x Leiarius marmoratus $(8.9 \mathrm{~g})$, el mejor resultado se observó con el tratamiento de 4.60 relación proteína:lípidos, donde hubo mayor ahorro de proteína por el efecto de los lípidos. En los estudios nombrados anteriormente fueron utilizadas, indistintamente, dietas comerciales, prácticas o semipurificadas, por ello los resultados no permiten concluir en relación con los requerimientos cuantitativos de lípidos y ácidos grasos para estas especies.

En larvas de Rhamdia, Uliana, Silva y Radünz Neto (2001), evaluaron la eficiencia de las dietas suplementadas con aceites de canola, soya, hígado de bacalao, girados o maíz, con una proporción de $5 \%$ de la dieta, encontrando mayor tasa de crecimiento específico los peces alimentados con las dietas que contenían aceite de canola e hígado de bacalao. Melo, Radünz Neto, Silva y Trombetta (2002) alimentaron juveniles de Rhamdia (21.58 g) durante 26 días con dietas prácticas, a base de hígado bovino y levadura de caña, suplementadas con $5 \%$ de aceites de: canola, hígado de bacalao o manteca de cerdo, encontrando que el rendimiento de la carcasa no fue afectado por las fuentes 
evaluadas, sin embargo, hubo mayor deposición de grasa en los peces alimentados con la manteca de cerdo. Losekann et al. (2008) evaluaron el efecto de la suplementadas con aceites vegetales (aceite de soya, canola o arroz) incluidos en 5 o $10 \%$ en dietas con $32 \%$ $\mathrm{PB}$, sobre el desarrollo corporal y composición de filete de juveniles Rhamdia, no encontraron diferencias entre los aceites y los niveles sobre los parámetros medidos, los peces alimentados con $10 \%$ de aceite depositaron más grasa en el filete. Parra et al. (2008) evaluaron la eficiencia alimenticia de dietas que contenían diferentes fuentes lipídicas (manteca de cerdo, aceite de canola y aceite de girasol) en reproductores hembras de Rhamdia quelen (peso inicial de $500 \mathrm{~g}$ ) hallando que el desempeño de las hembras y el desarrollo larval no fue afectado por las fuentes lipídicas evaluadas.

Los estudios reportados para las especies de la familia Pimelodidae relacionados con la suplementación de lípidos en el alimento, en general están enfocados principalmente a la evaluación de diferentes fuentes, proporciones y porcentajes de inclusión de este nutriente en las dietas para larvas, juveniles y reproductores.

\section{Carbohidratos}

Químicamente los carbohidratos son sustancias orgánicas que llevan en su molécula una o más veces la función alcohol, y la función aldehído o la función acetona. Aunque los carbohidratos no son un nutriente esencial, tienen importancia en las funciones biológica de los peces, constituyen una fuente básica de energía de algunos tejidos (Holt, 2011), son la fuente menos onerosa de energía y su utilización en dietas para acuicultura implica reducir costos. La ausencia de niveles adecuados de estos en la dieta lleva a un catabolismo de proteínas y lípidos para la síntesis de energía. Haciendo una inclusión adecuada de carbohidratos en la dieta puede disminuirse el uso de la proteína para generar energía y minimizar la emisión de compuestos nitrogenados en el agua (Fracalossi et al., 2013). El exceso de estos puede afectar adversamente parámetros morfométricos, fisiológicos y funcionales de los peces (Herme, Mommsen, \& Krogdahl, 2002). Sin embargo, se acepta generalmente que los peces no tienen un requisito específico para los carbohidratos de la dieta, pero es verificada la disminución de la tasa de crecimiento de varias especies cuando se alimentan con dietas totalmente exentas de este nutriente. En general, los peces tropicales de agua dulce presentan mayor capacidad de digestión y asimilación de carbohidratos que los peces marinos y de agua fría, así como los peces omnívoros y herbívoros demuestran ser más eficientes en el aprovechamiento de este nutriente que los carnívoros (Wilson, 1994). Los reportes en la literatura muestran una diferencia notable en las exigencias de carbohidratos para juveniles (peso húmedo inicial que oscila entre 1 y 120 g) de varias especies de Pseudoplatystoma, niveles óptimos que varían de 13 a $25 \%$ dependiendo de la calidad de los ingredientes y su inclusión en la dieta (Lundstedt et al., 2004; Okamura, 2009; Gonçalves, 2014). En particular, Gonçalves (2014), en P. reticulata encontró que el contenido de proteína puede reducirse a $36 \%$ cuando fueron valanciados otros nutrientes $(15 \%$ de carbohidratos y $8 \%$ de lípidos).

\section{Vitaminas y Minerales}

Las vitaminas son compuestos orgánicos de bajo peso molecular, requeridas en cantidades relativamente pequeñas, esenciales para la salud, crecimiento y reproducción de los organismos vivos. Teniendo en cuenta la importancia y el hecho de que estas sustancias no son sintetizadas, o las cantidades sintetizadas no son suficientes para atender las exigencias de los peces es imprescindible su suplementación en la dieta (de Borda, do Carmo, \& de Abreu, 2013).

Las vitaminas se clasifican en liposolubles (A, D, E y K) e hidrosolubles (B y C). Las vitaminas del complejo $\mathrm{B}$ actúan principalmente como coenzimas en varios procesos metabólicos. Las vitaminas liposolubles son absorbidas en el intestino conjuntamente con los lípidos de la dieta y almacenadas en el organismo cuando 
son ingeridas en cantidades superiores a las necesidades metabólicas de la especie, existiendo la posibilidad de acumularlas en exceso en los tejidos, produciendo toxicidad (hipervitaminosis). Las vitaminas hidrosolubles no son almacenadas en el organismo, la cantidad sobrante es excretada.

Los peces almacenan grandes cantidades de vitamina D en su hígado y tejido graso, incluyendo la grasa asociada con el músculo. Bajo circunstancias naturales la vitamina D planctónica se acumula en la cadena alimenticia. En acuicultura, es necesario suplementarla en las dietas. El papel de la vitamina D en la fisiología de los peces es todavía enigmático. Hasta la década de 1970 hubo consenso en que los peces acumulaban, pero no metabolizaban la vitamina D. En la actualidad es sustancialmente evidentes que los peces tienen un sistema endocrino de la vitamina $\mathrm{D}$ con funciones similares a la de los mamíferos (Lokc, Waagbø, Wendelaar-Bonga, \& Flik, 2010). La vitamina $\mathrm{K}$ se produce naturalmente como la filoquinona (vitamina K1) y la menaquinona (vitamina $\mathrm{K} 2$ ). Adicionalmente, hay una provitamina sintética, menadiona (vitamina K3), utilizada principalmente como fuente de vitamina $\mathrm{K}$ en el alimento animal. La vitamina $\mathrm{K}$ juega un papel vital en la coagulación sanguínea y en la mineralización ósea en peces, pero el requisito mínimo sugerido varía considerablemente dependiendo de la fuente de vitamina K utilizada. La deficiencia de vitamina $\mathrm{K}$ se caracteriza por mortalidad, anemia, Incremento del tiempo de coagulación sanguínea y alteraciones histopatológicas en hígado y branquias (Krossøy, Waagbø, \& Ørnsrud, 2011).

La vitamina $E$ impulsa mecanismos inmunológicos, hormonales y celulares, mejora las actividades fagocíticas y la producción de leucocitos. Además, en asociación con el selenio y el glutatión peroxidasa, la vitamina E evita la oxidación de macromoléculas. La vitamina E es importante para la salud animal, el crecimiento, el rendimiento productivo, la calidad de los filetes y los sistemas inmunológicos. Zanon, Silva, Cerozi y Cyrino (2018) evaluaron el efecto de la vitamina E $(3.4 ; 28.4 ; 53.4$;
$103.4 ; 153.4$ y $303.4 \mathrm{mg}$ de acetato de DL-a-tocoferol por $\mathrm{kg}$ de dieta) sobre la composición de la carne, el crecimiento, los parámetros bioquímicos e inmunológicos del Pseudoplatystoma reticulatum, concluyendo que con base en el contenido de globulina sérica y la deposición de la vitamina $\mathrm{E}$ en hígado y filete, se recomienda la inclusión de $166.6 \mathrm{mg} / \mathrm{kg}$ de acetato de tocoferol DL-alfa en la dieta para mejorar el estado inmunológico y, probablemente, la calidad de la carne de esta especie. Teniendo en cuenta que para las especies de la familia

CUADRO 3

Requerimiento vitamínico y mineral de Ictalurus punctatus

TABLE 3

Vitamin and mineral requirement of Ictalurus punctatus

\begin{tabular}{|c|c|}
\hline Nutriente & Requerimiento \\
\hline \multicolumn{2}{|l|}{ Microminerales (mg7kg) } \\
\hline Cobre & 5 \\
\hline Hierro & 30 \\
\hline Zinc & 20 \\
\hline Manganeso & 2.4 \\
\hline Selenio & 0.25 \\
\hline Yodo & 1.1 \\
\hline \multicolumn{2}{|l|}{ Macrominerales (\%) } \\
\hline Calcio & 1.5 \\
\hline Fósforo & 0.8 \\
\hline Relación Calcio:Fósforo & $1.5: 0.8$ \\
\hline Potasio & 0.26 \\
\hline Cloro & 0.17 \\
\hline Magnesio & 0.04 \\
\hline Sodio & 0.06 \\
\hline \multicolumn{2}{|l|}{ Vitaminas liposolubles } \\
\hline $\mathrm{A}(\mathrm{mg} / \mathrm{kg})$ & 0.6 \\
\hline $\mathrm{B}(\mu \mathrm{m} / \mathrm{kg})$ & 12.5 \\
\hline $\mathrm{E}(\mathrm{mg} / \mathrm{kg})$ & 50 \\
\hline \multicolumn{2}{|c|}{ Vitaminas hidrosolubles (mg/kg) } \\
\hline Tiamina & 1 \\
\hline Riboflavina & 9 \\
\hline Vitamina $\mathrm{B}_{6}$ & 3 \\
\hline Ácido pantoténico & 15 \\
\hline Niacina & 14 \\
\hline Ácido fólico & 1.5 \\
\hline Colina & 400 \\
\hline Vitamina $\mathrm{C}$ & 15 \\
\hline
\end{tabular}

(Fuente: NRC, 2011). 
Pimelodidae existe una escasa información con respecto al requerimientos de vitaminas se presentan los requerimientos de vitaminas del Ictalurus puntatus, que es un silúridos omnívoro (Cuadro 3).

Los minerales son elementos químicos inorgánicos que hacen parte de los organismos de los peces, son necesarios para el metabolismo y crecimiento. Sin embargo, a diferencia de lo que ocurre en el caso de los animales terrestres, que dependen por completo de un aporte de minerales en el alimento, los peces son capaces de absorber los minerales requeridos directamente del agua a través de las branquias y superficie corporal (Hepher, 1993). Los minerales se clasifican en macrominerales (como calcio, fósforo, potasio, magnesio, cloro $\mathrm{y}$ sodio), requeridos en mayor cantidad y microminerales (cobre, cobalto, cromo, yodo, hierro, manganeso, molibdeno, selenio y zinc), necesarios en pequeñísimas cantidades. La información respecto a la nutrición de minerales de peces es limitada comparada con los otros nutrientes.

\section{CONCLUSIONES}

La amplia diversidad, que se basa en el comportamiento alimenticio, morfología del tracto gastrointestinal y fisiología digestiva trófica que presenta el grupo de los silúridos, dificulta el acercamiento a la precisión de hábitos en las diferentes especies. Igualmente, las referencias disponibles para casos específicos también pueden generar dificultades interpretativas.

Estudios en una misma especie presentan amplios rangos entre los requerimientos nutricionales, esto se debe a diferencias en el tamaño de los peces, la digestibilidad y palatabilidad de los ingredientes que conformaban las dietas, el balance de aminoácidos, la relación energía:proteína, la tasa de alimentación, los parámetros analizados y los factores ambientales.

Se deben realizar estudios futuros para analizar las relaciones de la dieta de la especie con los recursos alimentarios disponibles en las regiones donde se cultivan.
Es necesaria más investigación en el campo de la nutrición, específicamente en el tema de requerimientos de especies de la familia Pimelodidae para optimizar el cultivo de ellas.

Declaración de ética: los autores declaran que todos están de acuerdo con esta publicación y que han hecho aportes que justifican su autoría; que no hay conflicto de interés de cualquier tipo; y que han cumplido con todos los requisitos y procedimientos éticos y legales pertinentes. El documento firmado se encuentra en los archivos de la revista.

\section{AGRADECIMIENTOS}

A la Dirección general de investigaciones de la Universidad de los Llanos por la financiación del proyecto C01-F01-021-2017.

\section{RESUMEN}

Los silúridos, también conocidos como bagres, es uno de los grupos más representativos de peces. Conformado por 31 familias, 412 géneros y 2600 especies aproximadamente, por lo que se ubica, en extensión, como el tercero entre todos los órdenes de teleósteos de los cuales 13 familias (64\% de las especies) residen en sur América. Dentro de este orden se encuentra la familia Pimelodidae, Eigenmann y Eigenmann (1889), siendo la más abundante en siluriformes neotropicales distribuidos ampliamente en América del Sur y Central. Algunos representantes de la familia Pimelodidae son individuos cuyas características específicas los hacen aptos para ser manejados en cautividad con fines comerciales. Uno de los principales factores negativos para hacer rentable este ejercicio comercial es la falta de conocimiento relacionado, entre otras cosas, con los elementos básicos que permitan formular dietas alimenticias bien equilibradas y que aporten al individuo los requerimientos nutricionales básicos para un óptimo desarrollo. Es por lo anterior, que se requiere realizar una recopilación bibliográfica general de los principales aspectos relacionados con la alimentación y nutrición de esta familia.

Palabras clave: proteína; lípidos; energía; peces; silúridos; alimentación.

\section{REFERENCIAS}

Abes, S. da S., Agostinho, A. A., Okada, E. K., \& Gomes, L. C. (2001). Diet of Iheringichthys labrosus 
(Pimelodidae, Siluriformes) in the Itaipu Reservoir, Paraná River, Brazil-Paraguay. Brazilian Archives of Biology and Technology, 44(1), 101-105.

Abumarca, M., \& Martins-Santos, I. C. (Octubre, 1996). Caracterização cromossômica de duas espécies da família Pimelodidae (Pisces; Siluriformes). VI Simpósito de Citogenética Evolutiva e Aplicada de peixes Neotropicaes. Universidad Federal de São Carlos, Brasil.

Acosta-Santos, A., Agudelo-Córdoba, E., Ajíaco, R., \& Ramírez-Gil, H. (2011). Leiarius marmoratus (Gill, 1870). Ficha Amazonas. En C. Lasso, E. AgudeloCórdoba, H. Ramírez-Gil, M. Morales-Betancourt, R. Ajiaco-Martínez, ... A. Sanabria-Ochoa (Eds.), Catálogo de recursos pesqueros continentales de Colombia (pp. 448-451). Bogotá, Colombia: Instituto de Investigaciones de Recursos Biológicos Alexander von Humboldt.

Andrade, P. M., \& Braga, F. M. S. (2005). Diet and feeding of fish from Grande River, located below the Volta Grande Reservoir, MG-SP. Brazil Journal Biology, 65(3), 377-385.

Arboleda, A. L. (1989). Biología pesquera de los grandes bagres del río Caquetá. Boletin Ecotrópica, 20, 3-54.

Arslan, M., Dabrowski, K., Ferrer, S., Dietrich, M., \& Rodríguez, G. (2013). Growth, body chemical composition and trypsin activity of South American catfish, surubim (Pseudoplatystoma sp.) juveniles fed different dietary protein and lipid levels. Aquaculture Reseach, 44, 760-771.

Baldisserotto, B., \& Neto, J. R. (2005). Jundia (Rhandia $s p$ ). En B. Baldisserotto \& L. de Carvalho-Gomes (Eds.), Espécies Nativas para a Piscicultura no Brasil (pp. 303-325). Santa Maria-RS: Editora da UFSM.

Becker, A., Jamile, V., Fabbrin, L. G., Oliveira, L. G., BehrII, E., Luhers, D., ... Baldisserotto, B. (2010). Morphometric parameters comparisons of the digestive tract of four teleosts with different feeding habits. Ciência Rural, 40(4), 862-866.

Beltran, C. \& Lamus, E. (1975). Contribución al conocimiento de la biología del bagre pintado Pseudoplatystoma (Linnaeus, 1766) y su importancia pesquera (Tesis de pregrado). Universidad de Bogotá Jorge Tadeo Lozano, Bogotá, Colombia.

Britz, P. J., \& Hecht, T. (1997). Effect of dietary protein and energy level on growth and body composition of South African abalone, Haliotus midae. Aquaculture, $156,195-210$.

de Borda, M. R., do Carmo, M. V., \& de Abreu, J. S. (2013). En D. Fracalossi \& J. Cyrino (Eds.), Nutriaqua. Nutrição e alimentação de espécies de interesse para a aquicultura brasileira ( $1^{\mathrm{a}}$ ed. ampliada) (pp. 121-166). Florianapolis, Brasil: Sociedate Brasileira de Aquacultura e Biologia Aquática.
Boscolo, W. R., Hayashi, C., \& Meurer, F. (2002). Digestibilidade aparente da energia e nutrientes de alimentos convencionais e alternativas para a Tilapia do Nilo (Oreochromis niloticus, L.). Brasileira Zootecnia, 31(2), 539-545.

Burguess, W. E. (1989). An atlas of freshwater and marine cat fishes: A preliminary survey of the siluriformes. New Jersey, USA: TFH Publications, Inc.

Campeche, D. F. B., Andrade, D. H. de H., Souza, A. M., Melo, J. F. B., \& Bezerra, R. de S. (2018). Dietary protein:lipid ratio changes growth, digestive enzyme activity, metabolic profile and haematological parameters in hybrid surubim (Pseudoplatystoma fasciatum $\times$ Leiarius marmoratus ). Aquaculture Research, 49(7), 2486-2494.

Campos, P., Martino, R., \& Trugo, L. C. (2006). Amino acid composition of Brazilian surubim fish (Pseudoplatystoma coruscans) fed diets with different levels and sources of fat. Food Chemistry, 96, 126-130.

Cardoso, P., \& Volpato, G. (2005). Chemical cues related to conspecific size in pintado catfish, Peudoplatystoma coruscans. Acta Ethologica, 8, 65-69.

Carneiro, D., \& Goncalves, E. (Noviembre, 2002). Exigência de proteína digestível em dietas práticas para pintado Pseudoplatystoma corruscans. XII Simpósio Brasileiro de Aquicultura. Goiânia, Brasil: Associação Brasileira de Aqüicultura ABRAQ.

Coldebella, I. J., Neto, J. R., Mallmann, C. A., Veiverberg, C. A., Bergamin, G. T., Pedron, F. A., \& Barcellos, L. J. G. (2011). The effects of different protein levels in the diet on reproductive indexes of Rhamdia quelen females. Aquaculture, 312(1-4), 137-144.

Cornélio, F., da Cunha, D., Silveira, J., Alexandre, D., Silva, C., \& Fracalossi, D. (2014). Dietary Protein Requirement of Juvenile Cachara Catfish, Pseudoplatystoma reticulatum. Journal of the World Aquaculture Society, 45(1), 45-53.

da Cunha, D. A., Cornélio, F. H. G., \& Fracalossi, D. M. (2015). Exigência de energia em dietas para juvenis de cachara, Pseudoplatystoma reticulatum. Boletim do Instituto de Pesca, 41(3), 567-578.

Cyrino, J., Fracalossi, D., \& Roubach, R. (2013). Avanços na Alimentação e Nutrição de Peixes carnívoros de Água Doce. Em D. Fracalossi \& J. Cyrino (Eds.), Nutriaqua. Nutrição e alimentação de espécies de interesse para a aquicultura brasileira $\left(1^{\mathrm{a}} \mathrm{ed}\right.$. ampliada) (pp. 283-295). Florianapolis, Brasil: Sociedate Brasileira de Aquacultura e Biologia Aquática.

Darias, M. J., Castro-Ruiz, D., Estivals, G., Quazuguel, P., Fernández-Méndez, C., Núñez-Rodríguez, J., \& Cahu, C. (2015). Influence of dietary protein and lipid levels on growth performance and the incidence of cannibalism in Pseudoplatystoma punctifer 
(Castelnau, 1855) larvae and early juveniles. Journal of Applied Ichthyology, 31, 74-82.

Días, A. L. (1987). Análises citogenéticas de peixes da família Pimelodidae (Pisces, Siluriformes) (Dissertação de Mestrado). Universidade Federal São Carlos, S. P. Brasil.

Duarte, S., Bemquerer, M., \& Araújo, F. G. (2015). Enzymatic Activity in the Gastrointestinal Tract of Pimelodus maculatus (Teleostei, Siluriformes) in Two Neotropical Reservoirs with Different Trophic Conditions. Brazilian Archives of Biology and Technology, 58(4), 605-612.

Elangovan, A., \& Shim, K. F. (1997). Growth response of juvenile Barbodes altus fed isocaloric diets with variable protein levels. Aquaculture, 158, 321-329.

Faccioli, C. K., Chedid, R. A., Mori, R. H., do Amaral, A. C., Belmont, R. A. F., Vicentini, I. B. F., \& Vicentini, C. A. (2016). Organogenesis of the digestive system in Neotropical carnivorous freshwater catfish Hemisorubim platyrhynchos (Siluriformes: Pimelodidae). Aquaculture, 451, 205-212.

Faccioli, C. K., Chedid, R. A., Mori, R. H., do Amaral, A. C., Vicentini, I. B. F., \& Vicentini, C. A. (2018). Cytochemical features of the digestive tract mucosa of Hemisorubim platyrhynchos (Siluriformes: Pimelodidae). Journal of Fish Biology, 92(6), 1915-1928.

Fagundes, C. K., Behr, E. R., \& Kotzian, C. B. (2008). Diet of Iheringichthys labrosus (Siluriformes, Pimelodidae) in the Ibicuí River, Southern Brazil. Iheringia. Série Zoologia, 98(1), 60-65.

Fenocchio, A. S., \& Bertollo, L. A. C. (1992). Karyotype similarities among Pimelodidae (Pisces, Siluriformes) from the Brazilian Amazon region. Cytobios, $69,41-46$.

Fenocchio, A. S., Cano, J., Sánches, S, Pastori, M. C., \& Alberdi, A. J. (1996). Caracterización cariotípica y consideraciones citotaxonómicas en Pimelodidae (Pisces, Siluroidei). III Reunión de Comunicaciones Cientificas y Tecnológicas. Universidad Nacional del Nordeste, Argentina.

Fracalossi, D., Oeda, M., Silva, T., \& Cyrino, J. (2013). Técnicas experimentais em Nutrição de peixes. Em D. Fracalossi \& J. Cyrino (Eds.), Nutriaqua. Nutrição e alimentação de espécies de interesse para a aquicultura brasileira (1 $1^{\mathrm{a}}$ ed. ampliada) (pp. 37-64). Florianapolis, Brasil: Sociedate Brasileira de Aquacultura e Biologia Aquática.

Fugi, R., Agostinho, A., \& Hahn, N. S. (2001). Trophic morphology of five benthic feeding fish species of a tropical floodplain. Revista Brasileira de Biologia, 61(1), 27-33.

Garcia, A. S., Goncalves, L. U., Cavalli, R. O., \& Viegas, E. M. M. (2013). Lípidos. En D. Fracalossi \& J.
Cyrino (Eds.), Nutriaqua. Nutrição e alimentação de espécies de interesse para a aquicultura brasileira ( $1^{\text {a }}$ ed. ampliada) (pp 79-100). Florianapolis, Brasil: Sociedate Brasileira de Aquacultura e Biologia Aquática.

Gayrord, T. G., \& Gatlin III, D. M. (2001). Dietary protein and energy modifications to maximize compensatory growth of channel catfish (Ictalurus punctatus). Aquaculture, 194, 337-348.

Gonçalves, A. F. N. (2014) Desempenho produtivo $e$ respostas fisiológicas de juvenis e cachara (Pseudoplatystoma reticulatum) alimentados com diferentes níveis de proteina e carboidrato [Produtível performance and physiological responses of juvenile cachara (Pseudoplatystoma reticulatum) fed with different levels of protein and carbohydrate.] (Master's thesis). Universidade Estadual Paulista, Campus Experimental de Dracena, Brazil.

Gonçalves, E. G., \& Carneiro, D. J. (2003). Coeficientes de digestibilidade aparente da proteína e energia de alguns ingredientes utilizados em dietas para o pintado (Pseudoplatystoma coruscans). Revista Brasilera de Zootecnia, 32(4), 779-786.

Herme, G. I., Mommsen, T. P., \& Krogdahl, Å. (2002). Carbohydrates in fish nutrition: effects on growth, glucose metabolism and hepatic enzymes. Aquaculture Nutrition, 8, 175-194.

Hernandez, D. R., Pérez-Gianeselli, M., \& Domitrovic, H. A. (2009). Morphology, histology and histochemistry of the digestive system of South American catfish (Rhamdia quelen). International Journal of Morphology, 27(1), 105-111.

Hepher, W. (1993). Nutrición de peces comerciales en estanques. México: Limusa.

Holt, G. J. (2011). Larval fish nutrition. West Sussex, Reino Unido: Willey-Blackwell.

Kaushik, S. J., \& Médale, F. (1994). Energy requirements, utilization and dietary supply to salmonids. Aquaculture, 124, 81-97.

Kim, J. D., \& Kaushik, S. J. (1992). Contribution of digestible energy from carbohydrates and estimation of protein / energy requirements for growth of rainbow trout (Oncorhynchus mytkiss). Aquaculture, 106, 161-169.

Krossøy, C., Waagbø, R., \& Ørnsrud, R. (2011). Vitamin K in fish nutrition. Aquaculture Nutrition, 17, 585-594.

Layman, C. A., Winemiller, K., Arrington, A., \& Jepsen, D. (2005). Body size and trophic position in a diverse tropical food web. Ecology, 86(9), 2530-2535.

Lima-Junior, S. E., \& Goiten, R. (2004). Diet and feeding activity of Pimelodus maculates (Osteichtyes, Pimelodidae) in the Piracicaba River (State of Sao Paulo, 
Brazil) - The effect of seasonality. Boletim do Instituto de Pesca, 30(2), 135-140.

Lock, E. J., Waagbø, R., Wendelaar-Bonga, S., \& Flik, G. (2010). The significance of vitamin D for fish: Review. Aquaculture Nutrition, 16, 100-116.

Losekann, M. E., Neto, J. R., Emanuelli, T., Pedron, F., Lazzari, R., Bergamin, G. T., ... Simões, R. (2008). Alimentação do jundiá com dietas contendo óleos de arroz, canola ou soja. Ciência Rural, 38(1), 225-230.

Lovell, T. (1998). Nutrition and feeding of Fish (2 $2^{\text {nd }}$ ed.). Boston, MA, USA: Kluwer Academic Publishers.

Lundberg, J. G., Linares, O. J., Antonio, M. E., \& Nass, P. (1988). Phractocephalus hemiliopterus (Pimelodidae, Siluriformes) from the upper miocene Urumaco formation, Venezuela: a further case of evolutionary stasis e local extinction among South American fishes. Journal of Vertebrate Paleontology, 8, 131-138.

Lundberg, J. G., Mago-Leccia, F., \& Nass, P. (1991). Exallodontus aguanai, a new genus and species of Pimelodidae (Pisces: Siluriformes) from deep river channels of South America, and delimitation of the subfamily Pimelodinae. Proceedings of the Biological Society of Washington, 104(4), 840-869.

Lundstedt, L. M., Melo, J. F., \& Moraes, G. (2004). Digestive enzymes and metabolic profile of Pimelodus coruscans (Teleostei: Siluriformes) in response to diet composition. Comparative Biochemistry and Physiology Part B, 137, 331-339.

Machado, J. H. (1999). Desempenho produtivo de juvenis de pintado (Pseudoplatystoma coruscans) arracoados com diferentes níveis de proteína e energia. Em J. E. P. Cyrino, L. E. Pezzato, \& V. S. Miyada (Eds.), Anais do Simpósio sobre Manejo e Nutrição de peixes III (pp. 89-96). Campinas, SP, Brasil: Colegio Brasileiro de Nutricao Animal (CBNA).

Marques, E. M., Agostinho, A. A., Sampaio, A. A., \& Agostinho, C. S. (1992). Alimimentaçao, evacuaçao gástrica e cronologia da digestao de jovens de pintada Pseudoplatystoma corruscans (Siluriformes, Pimelodidae) e suas relações com a temperatura ambiente. Revista Unimar, 14, 207-221.

Martino, R., Cyrino, J., Portz, L., \& Trugo, L. (2002a). Effect of dietary lipid level on nutritional performance of surubim, Pseudoplatystoma coruscans. Aquaculture, 209, 209-218.

Martino, R, Cyrino, J., Portz, L., \& Trugo, L. (2002b). Performance and fatty acid composition of surubim (Pseudoplatystoma coruscans) fed diets with animal and plant lipids. Aquaculture, 209, 233-246.

Martino, R. C., Cyrino, J. E. P., Portz, L., \& Trugo, L. C. (2005). Performance, carcass composition and nutrient utilization of surubim Pseudoplatystoma coruscans (Agassiz) fed diets with varying carbohydrate and lipid levels. Aquaculture Nutrutrition, 11, 131-137.

Melo, J. F. B, Lundstedt, L. M., Metón, I., Baanante, I. V., \& Moraes, G. (2006). Effects of dietary levels of protein on nitrogenous metabolism of Rhamdia quelen (Teleostei: Pimelodidae). Comparative Biochemistry and Physiology Part A: Molecular \& Integrative Physiology, 145(2), 181-187.

Melo, J. F. B., Radünz-Neto, J., Silva, J. H. S., \& Trombetta, C. G. (2002). Desenvolvimento e composição corporal de alevinos de jundiá (Rhamdia quelem), alimentados com dietas contendo diferentes fontes de lipídios. Ciência Rural, 32(2), 323-327.

Menin, E., \& Minura, O. M. (1992). Anatomia funcional comparativa do estomago de tres peixes teleostei de hábito alimentar onívoro. Revista Ceres, 39(233), 233-260.

Meyer, G., \& Fracalossi, D. M. (2004). Protein requirement of jundia fingerlings, Rhamdia quelen, at two dietary energy concentrations. Aquaculture, 240, 331343.

Milles, C. (1971). Los peces del río Magdalena (2a ed.). Ibague, Colombia: Universidad del Tolina.

Mora-Sánchez, J. A., Moyetones, F., \& Jover, M. C. (2009). Influencia del contenido proteico en el crecimiento de alevines de bagre yaque, Leiarius marmoratus, alimentados con concentrados comerciales. Zootecnia Tropical, 27(2), 187-194.

Moyle, P., \& Cech, J. 2004. Fishes: an Introduction to Ichtyology $\left(5^{\text {th }}\right.$ ed.). U.S.A.: Pearson Prestice Hall.

Murillo-Pacheco, R., Cruz- Casallas, N. E., Ramírez- Merlano, J., Marciales-Caro, L. J., Medina-Robles, V. M., \& Cruz-Casallas, P. E. (2012). Efecto del nivel de proteína sobre el crecimiento del yaque Leiarius marmoratus (Gill, 1870) bajo condiciones de cultivo. Orinoquia, 16(2), 52-61.

Neto, J. R., \& de Borda, M. R. (2013). Exigências Nutricionais e alimentação do jundiá. Em D. Fracalossi \& J. Cyrino (Eds.). Nutriaqua. Nutrição e alimentação de espécies de interesse para a aquicultura brasileira ( $1^{\text {a }}$ ed. ampliada) (pp 241-254). Florianapolis, Brasil: Sociedate Brasileira de Aquacultura e Biologia Aquática.

NRC. (1993). Nutrients requeriments of fish. Washington. D.C.: National Research Council.

NRC. (2011). Nutrients requeriments of fish. Washington. D.C.: National Research Council.

Okamura, D. (2009). Influencie do amido de milho no metabolismo energético de surubim Pseudoplatystoma spp. [The influencie of cornstarch on the energy metabolism of surubim Pseudoplatystoma spp.] (Doctoral dissertation). Universidade Federal de Lavras, Departamento de Zootecnia, Brazil. 
Oliveira, C., Almeida-Toledo, L. F., Foresti, F., Britski, H. A., \& Toledo, F. O. (1988). Chromosome Formulae of neotropical freshwater fishes. Revista Brasileira de Genética, 11(3), 577-624.

Parra, J. E. G, Neto, J. R., Veiverberg, C. A., Lazzari, R., Bergamin, G. T., Pedron, F., ... Sutili, F. J. (2008). Alimentação de fêmeas de jundiá com fontes lipídicas e sua relação com o desenvolvimento embrionário e larval. Ciência Rural, 38(7), 2011-2017.

Pereira, C., Smith, W. S., \& Espindola, G. (2004). Hábitos alimenticios de nueve especies de peces del embalse de Três Irmãos, São Paulo, Brasil. Universidad y Ciencia, I, 33-38.

Piedras, S. R. N., Pouey, J. L. O. F., Moraes, P. R. R., \& Rodrigues, F. V. (2006). Resposta de alevinos de jundiá (Rhamdia sp.) alimentados con diferentes níveles da proteína bruta e energia digestível. Revista Brasileira de Agrociencia, 12(2), 217-220.

de Pinna, M. C. C. (1993). Higher-level phylogeny of Siluriformes (Teleostei, Ostariphysi), with a new classification of the order (Unpublished doctoral Dissertation). City University of New York, USA.

de Pinna, M. C. C. (1998). Phylogenetic relationships of Neotropical Siluriformes (Teleostei: Ostariophysi): Historical overview and synthesis of hypothesis. In L. R. Malabarba, R. P. Reis, Z. M. Lucena, \& C. A. S. Lucena (Eds.), Phylogeny and Classification of Neotropical Fishes (pp. 279-330). Porto Alegre: Edipucrs.

Portz, L., \& Furuya, W. M. (2013). Energia, proteina e Aminoácidos. En D. Fracalossi, J. Cyrino (Eds.), Nutriaqua. Nutrição e alimentação de espécies de interesse para a aquicultura brasileira $\left(1^{\mathrm{a}}\right.$ ed. ampliada) (pp 65-78). Florianapolis, Brasil: Sociedate Brasileira de Aquacultura e Biologia Aquática.

Provenzano, F. R. (Octubre, 2002). Taxonomía de siluriformes: Aspectos generales. Memorias Diplomado Ecología y Diversidad de Peces Colombo-Venezolanos. Universidad del Valle, Cali, Colombia.

Ramírez, H., \& Ajiaco, R. E. (2001). La Pesca en la Baja Orinoquía Colombiana: una visión integral. Bogotá, Colombia: Ministerio de Agricultura, Instituto Nacional de Pesca y Acuicultura.

Ramírez, H., \& Ajiaco, R. E. (2011). Leiarius marmoratus (Gill, 1870). Ficha Orinoco. En C. Lasso, E. Agudelo-Córdoba, H. Ramírez-Gil, M. Morales-Betancourt, R. Ajiaco-Martínez, F. Gutiérrez, ... A. Sanabria-Ochoa (Eds.), Catálogo de recursos pesqueros continentales de Colombia (pp.451-454). Colombia: Instituto de Investigaciones de Recursos Biológicos Alexander von Humboldt.

Reidel, A., Boscolo, W. R., Feiden, A., \& Romagosa, E. (2010). The effect of diets with different levels of protein and energy on the process of final maturation of the gametes of Rhamdia quelen stocked in cages. Aquaculture, 298(3-4), 354-359.

Ringuelet, R. A., Aramburu, R. H., \& de Aramburu, A. (1967). Los peces argentinos de agua dulce. Buenos Aires, Argentina: Comisión de Investigaciones Científicas.

Roca-Lanao, B., Polonia-Rivera, C., Altamar, J., Duarte, L. O., \& Manjarrés-Martínez, L. (2016). Caracterización de granjas y evaluación de la producción de acuicultura en Colombia durante el año 2016: un análisis basado en once núcleos geográficos. Santa Marta, Colombia: Universidad del Magdalena y Autoridad Nacional de Acuicultura y Pesca (AUNAP).

Rodrigues, A., Pauletti, P., Kindlein, L., Francisquine, E., Possebon, E., \& Machado-Neto, R. (2010). Intestinal histomorphology in Pseudoplatystoma fasciatum fed bovine colostrum as source of protein and bioactive peptides. Scientia Agricola, 67(5), 524-530.

Salhi, M., Bessonart, M., Chediak, G., Bellagamba, M., \& Carnevia, D. (2004). Growth, feed utilization and body composition of black catfish, Rhamdia quelen, fry fed diets containing different protein and energy levels. Aquaculture, 231, 435-444.

Samantaray, K., \& Mohanty, S. S. (1997). Interations of dietary levels of protein and energy on fingerling snakehead, Chana striata. Aquaculture, 156, 241-249.

Santos, C. M., Duarte, S., Souza, T. G. L., Ribeiro, T. P., Sales, A., \& Araújo, F. G. (2007). Histologia e caracterização histoquímica do tubo gastrintestinal de Pimelodus maculatus (Pimelodidae, Siluriformes) no reservatório de Funil, Rio de Janeiro, Brasil. Iheringia. Série Zoologia, 97(4), 411-417.

Sargent, J. R., Tocher, D. R., \& Bell, J. G. (2002). The Lipids. In J. E. Halver \& R. W. Hardy (Eds.), Fish Nutrition $\left(3^{\text {th }}\right.$ ed). San Diego, California, USA: Academic Press.

de Seixas Filho, J. T., Fonseca, C. C., Oliveira, M. G., Donzale, J. E., \& Menin, E. (2001a). Determinação do Sistema endócrino difuso nos intestinos de Três Teleostei (Pisces) de Água Doce com Hábitos Alimentares Diferentes. Revista Brasileira de Zootecnia, 30(5), 1403-1408.

de Seixas Filho, J. T., de Moura Brás, J., Gomide, A. T. M., Oliveira, M. G. A., Donzele, J. L., \& Menin, E. (2001b). Anatomia funcional e morfometria do intestino no Teleostei (Pisces) de água doce surubim (Pseudoplatystoma coruscans - Agassiz, 1829). Revista Brasileira de Zootecnia, 30(6), 1670-1680.

Signor, A., Signor, A. A., Feide, A., Boscolo, W. R., Reidel, A., \& Hayashi, C. (2004). Exig ncia de proteõna bruta para alevinos de jundia Rhamdia quelen. Varia Scientia, 4(8), 79-89. 
Silva, T. S. C. (2013). Protein and energy requirements and evaluation of alternative protein sources for striped surubim Pseudoplatystoma fasciatum (Doctoral dissertation). Universidade de São Paulo, Escola Superior de Agricultura Luiz de Queiroz, Brazil.

de Silva, S. S. \& Anderson, T. A. (1995). Fish Nutrition in Aquaculture. London, Great Britain: Chapman \& Hall.

Shibatta, O. A., \& Dias, A. L. (Octubre, 1996). Proposta para utilização da análise cariotípica em populações alopátricas de Pimelodus maculatus Lacépede, 1803 (Pisces, Pimelodidae) na taxonomia da espécie. VI Simpósio de Citogenética Evolutiva e Aplicada de Peixes Neotropicaes. Universidad Federal de São Carlos, Brasil.

De Souza, G. A. L., Da Silva, L. K. S, Macedo, F. F., Lopera-Barrero, N., De Abreu, S. J., De Souza, F. P., \& Povh, J. A. (2017). Performance of Hybrid Catfish Subjected to Different Protein Levels. Boletim do Instituto de Pesca, 44, 113-120.

Souza, I. L., Moreira-Filho, O. E., Corrêa, E., \& Castro, R. M. (1994). Informações citogenéticas preliminares de uma nova espécie de Pimelodidae cego de cavernas (Itaetê, BA). V Simpósio de Citogenética Evolutiva e Aplicada de Peixes Neotropicaes. Universidad Estadual Paulista - Botucata, Brasil.

Swarca, A. C., Dias, A. L., \& Giuliano-Caetano, L. (1996). Análises cromossômicas em Pimelodus maculatus (Pisces, Pimelodidae) da bacia do rio Tibagi/PR. VI Simpósio de Citogenética Evolutiva e Aplicada de Peixes Neotropicaes. Universidad Federal de São Carlos, Brasil.

Tallarico, M. (1997). Surubim. Brasil: Ministerio de Medio Ambiente dos recursos hídricos da Amazônia legal, Instituto Brasileiro do Medio Ambiente e dos recursos naturais renováveis.

Tambani Da Silva, C., Dias, A. L., \& Giuliano-Caetano, L. (1996). Análise citogenética em Iheringichthys labrosus e Pimelodella sp (Pisces, Pimelodidae) da bacia do rio Tibagi/PR. VI Simpósio de Citogenética Evolutiva e Aplicada de Peixes Neotropicaes. Universidad Federal de São Carlos, Brasil.

Tucker, C., \& Robinson, E. (1991). Channel Catfish Farming Handbook. New York, USA: Van Nostrand Reinhold.
Uliana, O, Silva, J. H. S., \& Radünz-Neto, J. (2001). Diferentes fontes de lipídios testadas na criação de larvas de jundiá (Rhamdia quelen), Pisces, Pimelodidae. Ciências Rural, 31(1), 129-133.

Valbuena-Villareal, R. D., Zapata-Berruecos, B. E., \& Gutiérrez-Espinosa, M. C. (2012). Apparent digestibility coefficients of three protein ingredients in capaz, Pimelodus grosskopfii. Orinoquia, 16(1), 179-186.

Vissotto, P. C., Foresti, F. E., \& Oliveira, C. (1994a). Estudos citogenéticos em cinco espécies da família Pimelodidae (Pisces, Siluriformes). V Simpósio de Citogenética Evolutiva e Aplicada de Peixes Neotropicaes. Universidad Estadual Paulista - Botucata, Brasil.

Vissotto, P. C., Foresti, F., \& Oliveira, C. (1996). Estudos preliminares sobre o sistema ZZ/ZW de determinação sexual em Imparfinis mirini (Pisces, Siluriformes). VI Simpósio de Citogenética Evolutiva e Aplicada de Peixes Neotropicas. Universidad Federal de São Carlos, Brasil.

Vissotto, P. C., Maistro, E. L., Foresti, F., Oliveira, C. E., \& Carvalho, E. D. (1994b). Análises citogenéticas com relato de ocorrência de cromossomos B em Iheringichthys labrosus (Pisces, Siluriformes). V Simpósio de Citogenética Evolutiva e Aplicada de Peixes Neotropicas. Universidad Estadual Paulista Botucata, Brasil.

Ward-Campbel, B. M. S., Beamish, F. W. H., \& Kongchaiya, C. (2005). Morphological characteristiscs in relation to diet in five coexisting thai fish species. Journal of fish biology, 67, 1266-1279.

Wilson, R. (1994). Utilization of dietary carbohydrate by fish. Aquaculture, 124, 67-80.

Wilson, R., \& Poe, W. (1985). Apparent Digestible Protein and Energy Coeeddicients of Common Feed Ingredients for Channel Catfish. The Progressive FishCulturist, 47(3), 154-158.

Zanardi, M. F., Boquembuzo, J. E., \& Koberstein, T. C. R. D. (2008). Performance of pintado juveniles (Pseudoplatystoma coruscans) fed with three different diets. Ciências Agrárias e Ambientai, 6, 445-450.

Zanon, R. B., Silva, T. S. de C., Cerozi, B. da S., \& Cyrino, J. E. P. (2018). Effects of graded levels of dietary vitamin E on striped surubim Pseudoplatystoma reticulatum. Aquaculture Research, 49(4), 1423-1429. 